\title{
SILORANE BASED RESIN COMPOSITE VERSUS NANOHYBRID RESIN COMPOSITE: EFFECT OF PH OF STORAGE MEDIA ON VOLUMETRIC CHANGES AND ADAPTABILITY AT TOOTH/RESTORATION INTERFACE
}

\author{
Rehab MA Hamed ${ }^{*}$, Mohamed A Ezzat** and Inas A Elghandour ${ }^{* * *}$
}

\begin{abstract}
This study compared dimensional stability and adaptability of two resin composites [Filtek P90 and Filtek Supreme XT] after storage in different $\mathrm{pH}$ media.

Methods: For dimensional stability, cylindrical specimens were prepared either from Filtek P90 or Filtek Supreme XT. Specimens' dimensions were measured before and after storage in neutral [pH7] or acidic saliva [pH 3.6] for 1 week, 1month or 3 months. Volumetric changes were calculated. For adaptability, 80 class $\mathrm{V}$ cavities were made in sound human teeth. The cavities were restored with Filtek P90 or Filtek supreme XT. The adaptation was evaluated using stereomicroscope; before and after storage in acidic or neutral saliva for 1 week, 1 or 3 months.
\end{abstract}

Results: Filtek P90 showed significantly higher contraction compared to Filtek Supreme XT only after 3 months storage. After 1 week or 1 month, the difference in volumetric changes between two material was statistically non-significant. The $\mathrm{pH}$ of storage media showed non-significant effect on volumetric changes of both composites. For adaptability to cavity walls in acidic saliva, no statistically significant difference was found between gap dimensions at tooth restoration interface for both Filtek P90 and Filtek Supreme XT. However, in neutral saliva, Filtek P90 showed statistically significantly higher mean gap dimensions than Filtek Supreme XT through all time storage.

Conclusions: Silorane-based resin composite undergoes volumetric changes comparable to nanohybrid resin composite except on long term storage where it revealed contraction. The adaptation of silorane based composite was worse compared to that of nanohybrid composite in neutral $\mathrm{pH}$ media.

KEYWORD; silorane based resin composite; volumetric changes; adaptation

\footnotetext{
* Researcher, Faculty of Dentistry, Cairo University, Egypt

** Professor of Operative Dentistry, Faculty of Dentistry, Cairo University, Egypt

*** Associate Professor of Operative Dentistry, Faculty of Dentistry, Cairo University, Egypt
} 


\section{INTRODUCTION}

Resin composites have established essential role in dental practice. This results from its superior esthetics, conservation of tooth structure and improvements made in adhesive dentistry. However, methacrylate-based resin composites suffer from polymerization shrinkage and related polymerization stress. The interfacial stresses are governed by the degree of shrinkage and the ratio of free to bonded interfaces [cavity configuration or C-factor] ${ }^{(1)}$. These stresses might lead to cuspal deflection, micro cracks, marginal gaps and leakage, bacterial ingress and recurrent caries ${ }^{(2)}(3)$.

Trials have been made to reduce polymerization shrinkage by altering the filler content or the matrix resin. Different compositions of resin matrices have been employed. These comprise silorane; a hybrid monomer system that contain siloxane and oxirane molecules, where siloxane imparts hydrophobicity and oxirane imparts high reactivity and less shrinkage during polymerization. Marginal integrity and microleakage of silorane based restorative systems have been found to be better than methacrylates based system ${ }^{(4)(5)}$. Researchers attributed this to ring opening of silorane molecules during polymerization that reduce resulting shrinkage ${ }^{(6)}$. Maghaireh et al ${ }^{(1)}$ found that trials to reduce shrinkage by ring-opening polymerization of silorane based resin composites is not yet conclusive in terms of efficacy

Resin composite restoratives undergo dimensional changes during and following polymerization because of interaction with the humid oral environment ${ }^{(7)}{ }^{(8)}$. A major goal in restorative dentistry is to control the marginal gaps resulting from these dimensional changes. Dimensional stability of resin composites is influenced by polymerization shrinkage, coefficient of thermal expansion and contraction as well as interaction with oral environment. Uptake of water or solvent might lead to two opposing processes.
Unreacted components might be released by solvent resulting in shrinkage and deterioration of mechanical properties. On the other hand, solvent uptake might cause swelling of composite with resulting expansion. Thus, the dimensional stability of resin composite in a solvent is complex and cannot be predicted ${ }^{(9,10)}$. This was for dimethacrylate based composite but for silorane based composite limited data was found. The study of dimensional changes is needed to predict the clinical performance of restorative materials.

The oral environment and hence the tooth surfaces might have variable $\mathrm{pH}$ that affects water sorption and solubility of resin composite restoratives. The moisture in the oral environment may cause chemical degradation of resin composite as a result of hydrolysis. Enzymatic hydrolysis of resin composite might occur. The amount of degradation and leakage was shown to be time dependent $^{(\mathbf{1 1})}$.

So, the present study aimed to compare the dimensional stability of silorane based composite resin to methacrylate based composite resin before and after immersion in different $\mathrm{pH}$ storage media [acidic or neutral] over different periods of time [1 week, 1month and 3 months]. In addition, the adaptability of a silorane and a methacrylate based composite to cavity walls was evaluated.

\section{MATERIALS AND METHODS}

Two types of resin composite restorative materials were used in this study; a silorane based resin composite [Filtek P90] used with a P90 silorane adhesive system and a nano-hybrid resin composite [Filtek supreme XT] used with Adper single bond 2. Universal A3 shade was selected for both resin composites.

\section{Volumetric changes:}

Mold fabrication: A splitted circular Teflon mold was especially fabricated for the present 
study. The mold was splitted to facilitate removal of polymerized restorative material. It has dimensions of $3 \mathrm{~cm}$ in diameter and $3 \mathrm{~mm}$ in height. It is surrounded by a metal ring to confine the mold during material application. The mold had a central hole of $2 \mathrm{~mm}$ height and $3 \mathrm{~mm}$ diameter in which the restorative material is applied during specimen fabrication.

Preparation of storage media: The storage media used in the present study was artificial saliva prepared in the laboratory of Faculty of Pharmacy [Cairo University]. Its composition was sodium carbonate $\left(\mathrm{NaHCO}_{3}\right)$, disodium hydrogen phosphate $\left(\mathrm{Na}_{2} \mathrm{HPO}_{4}\right)$, anhydrous calcium chloride $\left(\mathrm{CaCl}_{2}\right)$ and water $\left(\mathrm{H}_{2} \mathrm{O}\right)^{(12)}$. It was either adjusted to $\mathrm{PH} 7$ by adding sodium hydroxide to represent neutral saliva media or adjusted to $\mathrm{PH} 3.6$ by adding lactic acid to represent acidic saliva. $\mathrm{pH}$ of storage media was measured using digital bench top $\mathrm{pH}$-meter (Hana, Romania).

Specimens' preparation: A total of sixty specimens were prepared for the study. Thirty specimens were prepared from silorane based composite [Filtek P90] and thirty specimens were prepared from nanohybrid resin composite [Filtek supreme XT]. The restorative material was applied inside central hole of the Teflon mold and cured following the manufacturer instructions as follow: The mold was held over a flat glass slab. The restorative material was packed inside the mold. A celluloid strip was placed against the surface and excess material was removed before curing. LED light device (PM-LED01, china) was used for curing with light intensity of $1200 \mathrm{mw} / \mathrm{cm}^{2}$. The light tip was placed contacting the celluloid matrix. Curing was made for 20 seconds from each side of the mold

Measurement of specimen dimensions (prestorage measurement): Before storage in artificial saliva, measurements of the length and diameter of each specimen was carried out with a digital caliper (0-150mm, H Y, china). Measurements were recorded in millimeters.
Specimens' storage: immediately after curing, half of the specimens of each material was immersed in neutral saliva (ph7) and the other half was submerged in acidic saliva (ph3.6) at room temperature. Specimens were divided into three subgroups according to storage period; either one week, one or three months. For one-week storage period, the artificial saliva was not changed. For one and three-month storage, saliva was changed every week.

Measurment of specimen dimensions (post-storage measurement): Specimens were blot dried and specimens' dimensions were measured after storage using a digital Caliper in the same way as prestorage measurement. The dimensional changes in length and diameter (differences) were calculated by subtracting the pre- storage measurements from post-storage measurements. Then volume was calculated using mathematical formula:

Where: is volume of specimen is constant equal 3.14 the radius $h$ is $h$ the length

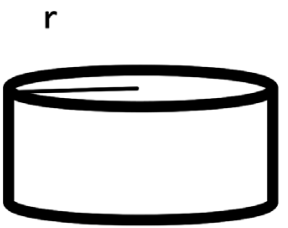

\section{Tooth/restoration interface examination:}

Specimen preparation: Eighty non-carious sound human teeth were selected for the present study. Teeth were cleaned, scaled then stored in distilled water at room temperature till usage. On the buccal surface of teeth, standardized class V cavities were prepared (1 $1 \mathrm{~mm}$ depth, $2 \mathrm{~mm}$ width, $2 \mathrm{~mm}$ in height) using an inverted cone carbide bur (H2, 016, Komet, Germany) and a fissure carbide bur (H2 ,016, Komet, Germany) under air water coolant. Depth was standardized by using a marked inverted cone bur during the preparation. Meanwhile, width and height were standardized by drawing the cavity on a sticker paper with the required dimensions. Then the space of the cavity was cut in the sticker using a cutter. The sticker was then tightened to the tooth and cavity preparation 
was made. Prepared cavities were filled with either Filtek P90 or Filtek supreme XT following the manufacturers' directions as follow:

For silorane based resin composite; Filtek P90/ Filtek P90 adhesive system: silorane primer was applied for 15 seconds on enamel and dentin, lightly air dried and then cured for 10 seconds using a LED light curing device (PM-LED01, china) with light intensity $1200 \mathrm{mw} / \mathrm{cm}^{2}$. Silorane bond was applied for 15 seconds, gently dispersed with air and cured for 10 seconds using LED device. Then, silorane based composite was packed into cavity in bulk, contoured to anatomical surface and cured for 20 seconds using LED device.

For nanohybrid resin composite; Filtek Supreme XT/Adper single bond2: Scotchbond etchant was applied to enamel and dentin by etchant syringe. It was left for 15 seconds and rinsed with oil free water for 10 seconds. The cavity was blot dried. Adper single bond2 was applied to the walls for 15 seconds, gently air dried for 5 seconds using oil free air and cured by LED light curing device (PM-LED01) for 10 seconds with light intensity $1200 \mathrm{mw} / \mathrm{cm}^{2}$. Cavities were filled with nanohybrid resin composite using bulk packing technique, contoured to the anatomical surface and light cured for 20 seconds in direct contact with the surface of restoration using LE D light curing device.

\section{Specimens' storage:}

Each group was divided into two equal sub groups according to storage media (artificial saliva) either neutral or acidic medium. Then each subgroup was further divided into four equal divisions (5 specimens each) according to time of storage (before storage, one week, one month, three months). Specimens were stored the same way as in dimensional changes.

\section{Tooth/ restoration interface examination:}

Specimens were longitudinally sectioned in a bucco-lingual direction into two halves using a slow speed diamond disc $(0.15 \mathrm{~mm}$, ESPE. Premier) under water coolant. For each specimen, a stereomicrograph was captured by a digital camera (DP10, Olympus, Japan) mounted on a Zoom Stereo microscope (SZ-PT, Olympus, Japan) at a magnification 30x. Images were then analyzed by the computer system. Tooth/restoration interface was evaluated using image analysis software (Image J, 1.41a, NIH, USA). Phase analysis was calculated automatically to give the gap dimensions between the filling material and cavity walls along the occlusal (4 points), axial (8 points) and gingival (4 points) walls. These points were chosen randomly where more gaps were seen. Surface area of gaps was also calculated by the software (figure 1). The collected data was tabulated using Microsoft Excel. The mean gap width (in microns) and surface area for each specimen was then calculated and subjected to statistical analysis.

\section{Statistical Analysis:}

Data was presented as means and standard deviation (SD) values. Due to the non-parametric distribution of data, non-parametric tests were used for statistical analysis. Mann-Whitney U test was used to compare between the two resin composites and two storage media. Kruskal-Wallis test was used to compare between the three storage times. If Kruskal-Wallis test was found significant, it was followed by Mann-Whitney U test for pair-wise comparisons between the groups. The significance level used was at $P$ value $\leq 0.05$. Statistical analysis was performed with SPSS 16.0 (Statistical Package for Scientific Studies) for Windows.

\section{RESULTS}

Volumetric dimensional changes:

Comparison of volumetric changes of the two resin composites using Mann-Whitney $U$ test revealed that after storage of Filtek P90 and Filtek Supreme XT in acidic artificial saliva for 1 week and 1 month, statistically non -significant difference was 


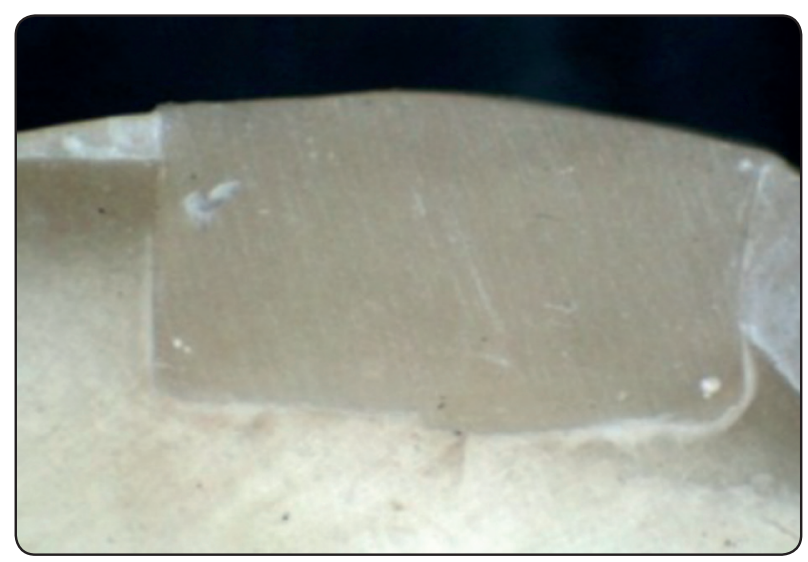

Fig. (1a) The photomicrograph after automatic correction of brightness and contrast.(original magnification x30)

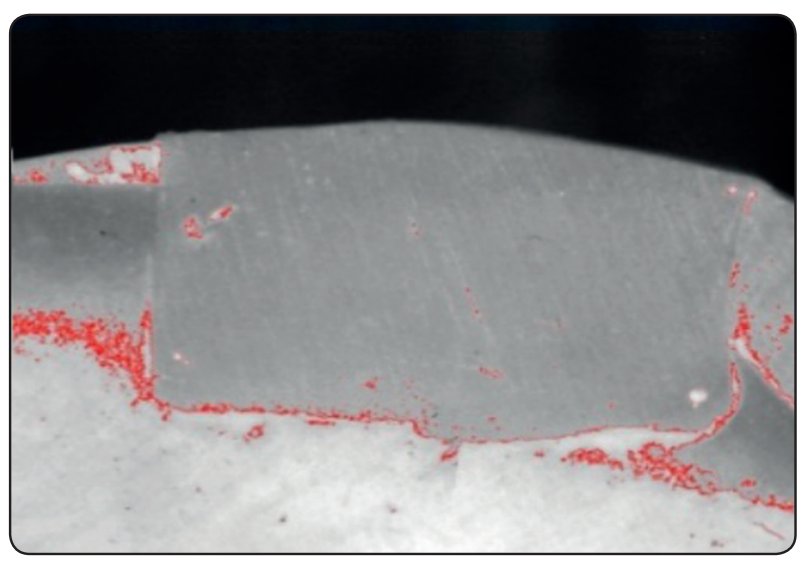

Fig. (1c) The gap areas were phase color-coded prior to calculation.

found between their volumetric changes. However, after 3 months, Filtek P90 showed statistically significantly higher mean volumetric contraction than Filtek Supreme XT at P-value $\leq 0.05$. In neutral saliva, Filtek P90 and Filtek Supreme XT showed statistically non-significant differences in their volumetric changes after 1 week. On the other hand, after 1month and 3 months, Filtek P90 showed statistically significantly higher mean volumetric contraction than Filtek Supreme XT at P-value $\leq$ 0.05 . This was shown in table (1).

The effect of storage media on volumetric changes of two resin composites using Mann-Whitney U test

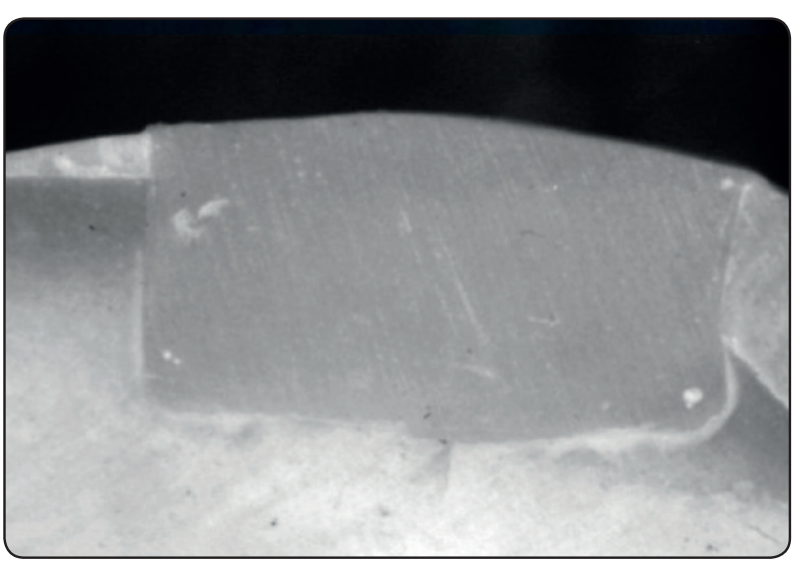

Fig. (1b) The previous photomicrograph after conversion into 8-bit monochrome image for detection of grey scale of gap areas.

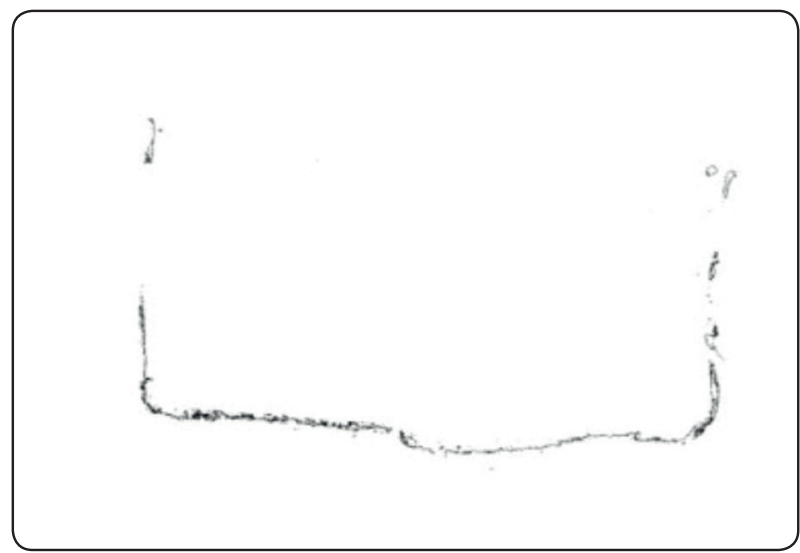

Fig. (1d) Binary threshold of the coded areas was done prior to calculation of gap dimensions and surface area of gap used for morphometric assessment.

was shown in table (2). It revealed that after storage of Filtek P90 and Filtek Supreme XT in acidic and neutral artificial saliva for 1 week, 1 and 3 months, statistically non- significant difference was found between their volumetric changes at $\mathrm{P}$-value $>0.05$.

Comparison of effect of storage time on volumetric changes of tested resin composites using Kruskal-Wallis test revealed that after 3 months storage, Filtek P90 showed statistically significantly highest mean volumetric contraction than one week and 1 month at P-value $\leq 0.05$. On the other hand, Filtek Supreme XT stored in acidic and artificial saliva after different periods of time showed 
statistically non- significant difference between its volumetric changes at $\mathrm{p}$-value $>0.05$. This was presented in table (3).

\section{Gap dimensions at Tooth restoration interface:}

Comparison of the two tested resin composites revealed that Filtek P90 showed higher gap dimensions compared to Filtek Supreme XT at different storage time. However, the differences in gap dimensions were statistically non-significant in acidic saliva but statistically significant in neutral saliva at $\mathrm{P}$-value $\leq 0.05$. This was represented by mean of gap dimensions at occlusal, axial and gingival walls in figure (2).
Comparison of two storage media using MannWhitney $U$ test revealed that after storage of Filtek P90 and Filtek Supreme XT in acidic and neutral artificial saliva for 1 week, 1 month and 3 months, statistically non- significant difference was found between their mean gap dimension at P-value > 0.05 . This was evident at the gingival, axial and occlusal wall. Mean of all walls is represented in figure (3).

Comparison of gap dimensions at tooth restoration interface as affected by storage time showed that on storage, time had statistically nonsignificant effect on adaptability of both Filtek P90 and Filtek supreme XT figures (4).

TABLE (1): The means, standard deviation (SD) values of volumetric changes of the two resin composites

\begin{tabular}{|c|c|c|c|c|c|c|}
\hline \multirow[b]{2}{*}{ pH } & \multirow{2}{*}{$\begin{array}{l}\text { Resin composite } \\
\text { Time }\end{array}$} & \multicolumn{2}{|c|}{ Silorane } & \multicolumn{2}{|c|}{ Nano-hybrid } & \multirow{2}{*}{$P$-value } \\
\hline & & Mean & SD & Mean & SD & \\
\hline \multirow{3}{*}{ Acidic } & 1 week & 0 & 0 & 0 & 0 & 1.000 \\
\hline & 1 month & 0.000008 & 0.00001 & 0 & 0 & 0.094 \\
\hline & 3 months & 0.0001 & 0.00006 & 0 & 0 & $0.036 *$ \\
\hline \multirow{3}{*}{ Neutral } & 1 week & 0 & 0 & 0 & 0 & 1.000 \\
\hline & 1 month & 0.000005 & 0.000003 & 0.0000002 & 0.000001 & $0.031 *$ \\
\hline & 3 months & 0.00002 & 0.00001 & 0.0000006 & 0.00001 & $0.028 *$ \\
\hline
\end{tabular}

*: Significant at $P \leq 0.05$

TABLE (2): The means, standard deviation (SD) values and results of comparison between volumetric changes after storage in acidic and neutral storage media

\begin{tabular}{|c|c|c|c|c|c|c|}
\hline \multirow{2}{*}{$\begin{array}{c}\text { Resin } \\
\text { composite }\end{array}$} & \multirow{2}{*}{ Time } & \multicolumn{2}{|c|}{ Acidic } & \multicolumn{2}{c|}{ Neutral } & \multirow{2}{*}{$\boldsymbol{P}$-value } \\
\cline { 2 - 7 } & Mean & SD & Mean & SD & \multicolumn{1}{|c|}{$\mathbf{1 . 0 0 0}$} \\
\hline \multirow{3}{*}{ Silorane } & $\mathbf{1}$ month & 0.000008 & 0.00001 & 0.000005 & 0.000003 & $\mathbf{0 . 9 1 3}$ \\
\cline { 2 - 7 } & $\mathbf{3}$ months & 0.0001 & 0.00006 & 0.00002 & 0.00001 & $\mathbf{0 . 1 3 8}$ \\
\hline \multirow{3}{*}{ Nano-hybrid } & $\mathbf{1}$ week & 0 & 0 & 0 & 0 & $\mathbf{1 . 0 0 0}$ \\
\cline { 2 - 7 } & $\mathbf{1}$ month & 0 & 0 & 0.0000002 & 0.000001 & $\mathbf{0 . 9 8 9}$ \\
\cline { 2 - 7 } & $\mathbf{3}$ months & 0 & 0 & 0.0000006 & 0.00001 & $\mathbf{0 . 4 0 1}$ \\
\hline
\end{tabular}


Table (3) The means, standard deviation (SD) values and results of comparison between volumetric changes after 1 week, 1 month and 3 months

\begin{tabular}{|c|c|c|c|c|c|c|c|c|}
\hline \multirow{2}{*}{$\begin{array}{c}\text { Resin } \\
\text { composite }\end{array}$} & pHime & \multicolumn{2}{|c|}{ 1 week } & \multicolumn{2}{|c|}{ 1 month } & \multicolumn{2}{c|}{ 3 months } \\
\cline { 2 - 9 } & Mean & SD & Mean & SD & Mean & SD & P-value \\
\hline \multirow{2}{*}{ Silorane } & Acidic & $0^{\mathrm{b}}$ & 0 & $0.000008^{\mathrm{b}}$ & 0.00001 & $0.0001^{\mathrm{a}}$ & 0.00006 & $\mathbf{0 . 0 0 5}$ \\
\cline { 2 - 9 } & Neutral & $0^{\mathrm{b}}$ & 0 & $0.000005^{\mathrm{b}}$ & 0.000003 & $0.00002^{\mathrm{a}}$ & 0.00001 & $\mathbf{0 . 0 0 3}$ \\
\hline \multirow{2}{*}{$\begin{array}{c}\text { Nano- } \\
\text { hybrid }\end{array}$} & Acidic & $0^{*}$ & 0 & 0 & 0 & 0 & 0 & $\mathbf{1 . 0 0 0}$ \\
\cline { 2 - 10 } & Neutral & 0 & 0 & 0.0000002 & 0.000001 & 0.0000006 & 0.00001 & $\mathbf{0 . 7 9 2}$ \\
\hline
\end{tabular}

*: Significant at $P \leq 0.05$, Means with different letters are statistically significantly different according to Mann-Whitney $U$ test

$\square$ Silorane $\square$ Nano-hybrid

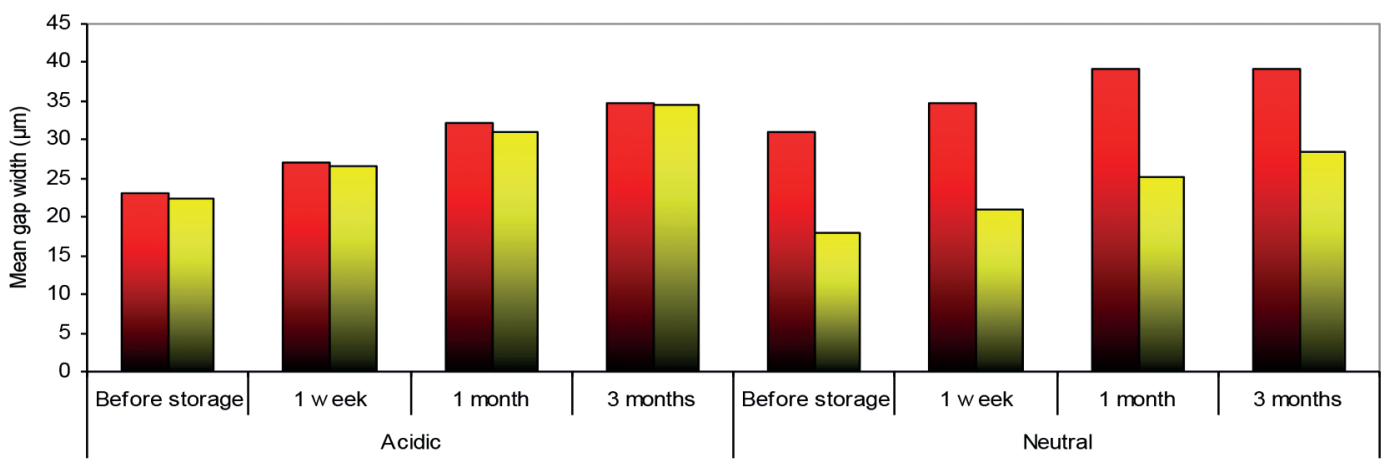

Fig. (2): Bar chart representing overall mean gap width of the two resin composites

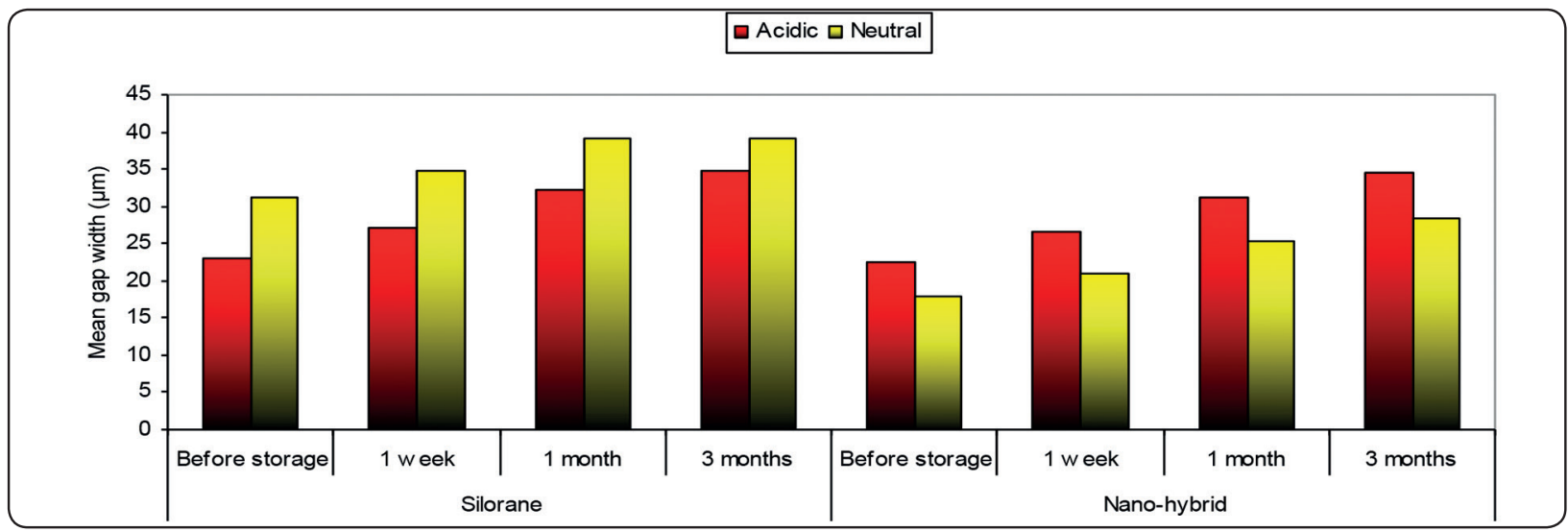

Fig. (3): Bar chart representing overall mean gap width in acidic and neutral artificial saliva 


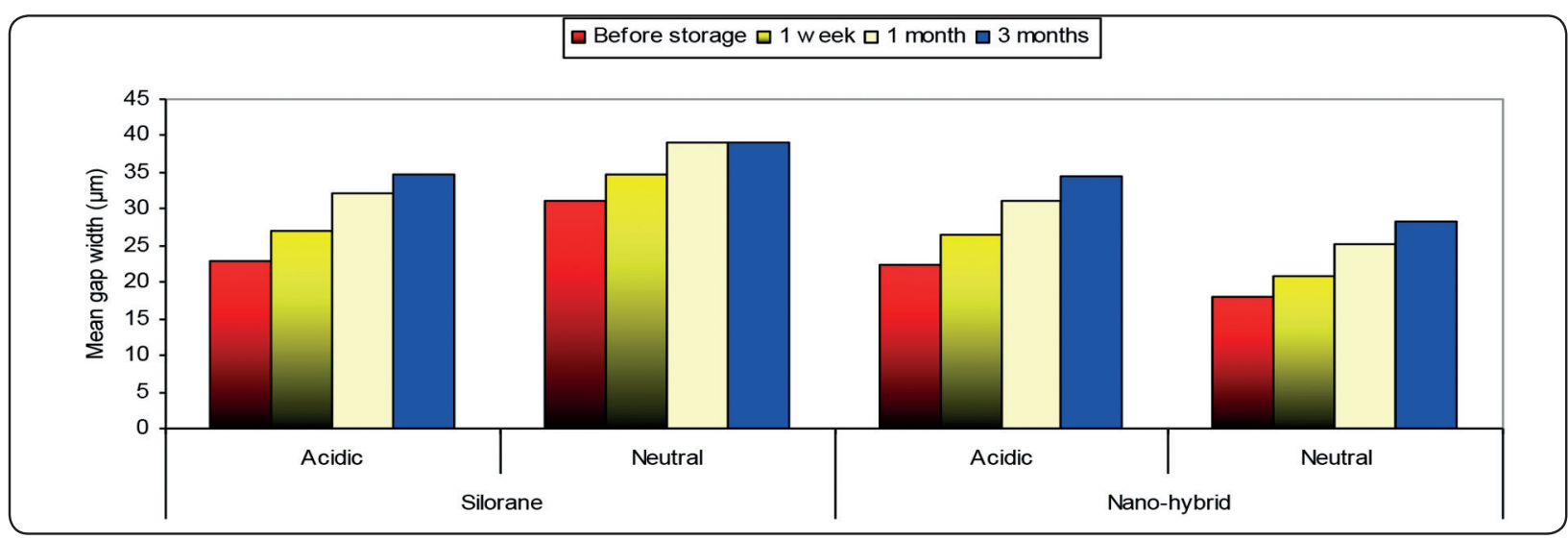

Fig. (4): Bar chart representing overall mean gap width through different storage times

\section{DISCUSSION}

In this study, dimensional stability of two resin composites was monitored by two ways: first measuring their dimensional changes and second by measuring the gaps that might occur at the tooth restoration interface because of such dimensional changes. The dimensional stability was monitored under acidic and neutal $\mathrm{PH}$ of artificial saliva at different time periods (one week, one month or three months). Filtek supreme XT was selected to represent nanohybrid composite that contains nanomeric particles and nanoclusters as inorganic fillers. Filtek P90 was selected as representative of siloranes to compare its dimensional changes and adaptability to that of a nanohybrid. Silorane based composite resin has been introduced aiming to reduce polymerization shrinkage where the silorane monomers undergoes polymerization through cationic ring opening ${ }^{(13)}$.

After polymerization, resin based restoratives would be reacting constantly with the oral environment. The principal interaction occurs with water which diffuses into the resin matrix with resulting two opposing phenomena. The first one involves leaching out of free unreacted monomers by water. This outward movement of monomer might lead to further shrinkage and hence loss of weight of the restorative material. On the other hand, hygroscopic absorption of water leads to expansion of the material. The amount and rate of water absorption had been shown to be diffusion dependent ${ }^{(7)}$. Versluis et al ${ }^{(8)}$, had found that within 4 weeks, polymerization shrinkage of resin composite was compensated by hygroscopic expansion and this caused reduction of contraction gaps. So, one of the storage periods selected in this study was 1 month.

Artificial saliva was used as a storage media. Ilie and Hickel ${ }^{(14)}$ had found that on exposure of resin composite materials to water, more components of filler particles leached into artificial saliva compared to distilled water. The $\mathrm{pH}$ of 3.6 was used in accordance with other researchers ${ }^{(15)(16)}$ who revealed that this is the lowest $\mathrm{pH}$ detected orally.

Results in the present study revealed that volumetric changes of Filtek P90 and Filtek Supreme XT were statistically non- significant after one week. However, after 3 months Filtek P90 showed higher contraction than Filtek Supreme XT. The difference between two materials after 3 months might be contributed to gradual leaching of ions and unreacted monomers into artificial saliva which lead to loss of volume (false shrinkage) for Filtek P90. In nanohybrid composite, due to hydrophilicity, solvent 
uptake compensates this false shrinkage leading to non-statistical volumetric changes but silorane is hydrophobic, so less solvent uptake occurs with resulting higher mean volumetric dimensional shrinkage than nanohybrid resin composite. This explanation was in accordance with Ortengren et al ${ }^{(11)}$ who found that resin composites based on hydrophobic matrices exhibited lower water sorption compared to resin composites based on more hydrophilic matrices. Martin et al ${ }^{(10)}$ stated that the hydrophilicity of the resin matrix would affect the degree of diffusion of water molecules inside the matrix. Meanwhile the elasticity and the bond strength would determine the amount of materials' expansion. They also found that the leaching of ionic species from the material followed an osmotic gradient. Martin and Jedynakiewic (7) found that water sorption and hence expansion of hydrophilic resins is more compared to hydrophobic resins which allow very little hydroscopic expansion. Chutinan et al ${ }^{(17)}$ found that the water sorption and hence expansion of resin composites continued up to 56 days. Ilie and Hickel ${ }^{(14)}$ found that Silorane based composites when compared to conventional methacrylate based composite, they revealed a decreased water sorption and associated diffusion coefficient. On the other hand, the results of the present study disagreed with other researchers ${ }^{(3)(18)}$ who stated that hydrophobic nature of the silorane molecule may improve hydrolytic stability of resin composites up to 26 week immersion compared with conventional methacrylate based material. However, in their study distilled water was used as storage media unlike the present study where artificial saliva was used.

Considering the effect of $\mathrm{pH}$ on volumetric changes, it was found that the changes of $\mathrm{pH}$ of artificial saliva showed no effect on the resulting volumetric changes of Filtek P90 and Filtek supreme XT through all storage periods. This might be correlated to storage of specimens at room temperature which decreased the effect of
$\mathrm{pH}$ of storage media. This agrees with Martin and Jedynakiewic ${ }^{(7)}$ who found that the $\mathrm{pH}$ of the immersing solution might have reduced effect on dimensional changes of resin composite restorative materials. Prakkia et al ${ }^{(15)}$ concluded that the effect of slightly low pH mediums seems to be slow acting and to accelerate dental composite hydrolysis high alkaline or very low acidic media would be used. On the other hand, the results disagreed with Ortengren et al (11) who found that the $\mathrm{pH}$ of the solution had influenced the solubility of different composite resin materials at $37^{\circ} \mathrm{C}$. however, the temperature of storage was different from that used in the present study. It also disagreed with Martin et al ${ }^{(10)}$ who found that when the $\mathrm{pH}$ of oral cavity is low, Ariston $\mathrm{pH}$ releases significantly more active substances than with neutral $\mathrm{pH}$. In our study, different brands of resin composites were used.

Considering the effect of time on volumetric changes of Filtek P90 and Filtek Supreme XT, it was found that after 3 months Filtek P90 contracted after storage but the volumetric changes of Filtek Supreme XT was not evident. This could be due to hydrophilicity of the resin composite or hydrophobicity of silorane backbone that affect water sorption. One week might not be enough time to examine dimensional change, significant changes were observed for up to 90 days, this explanation was in accordance with other researchers ${ }^{(8)}{ }^{(19)}$ who found that water sorption by resin composite is a process controlled by diffusion of water through the resin matrix and most degradation processes are diffusion rate dependent. Other researchers ${ }^{(7)}(20)$ stated that during 30 days storage period, leaching of resin composite components into the immersion solutions was not significantly evident. On the other hand, the results disagreed with Ortengren et al ${ }^{(11)}$ who found that resin composite leaches most of their organic components in the first 7 days following curing when distilled water was used as the immersion media. Also, our results disagreed with other researchers ${ }^{(10)}(21)$ who found that resin 
based composite restorative materials attained over $90 \%$ of their volumetric expansion within 7-10 days at $37^{\circ} \mathrm{C}$.

Considering adaptation of tested resin composites, class V cavities were prepared in sound teeth. Teflon molds were not used as Teflon material is non-reactive. So, there would be little interaction between the material and the mold affecting the final adaptability of the restorative materials. The smaller marginal gaps observed in natural teeth compared to Teflon molds, showed that the adhesion between the restoration and cavity walls has an important effect on marginal gap formation ${ }^{(22)}$. Also, in case of free expansion situations, the degree of expansion would be more relative to constraining dental cavity ${ }^{(18)}$.

In the present study, the results of adaption to cavity walls revealed that Filtek P90 showed more gap dimensions compared to Filtek Supreme XT which was statistically significant in neutral artificial saliva throughout all tested storage times. This could be due to high viscosity of Filtek P90 in comparison with Filtek Supreme XT, so more gaps would be found in Filtek P90. This was in accordance to Peutzfeldt and Asmussen ${ }^{(23)}$ who found a linear correlation between viscous flow and gap formation. The gaps were more evident in neutral artificial saliva as Filtek Supreme XT behaved differently in neutral and acidic media. It is hydrophilic so, in neutral storage media gaps formed could be compensated by water sorption, but in acidic media, the byproduct of hydrolysis is methacrylic acid that affects interaction of the matrix with acidic media, unlike Filtek P90 which is hydrophobic. This was in accordance with Weinmann et al ${ }^{(6)}$ who concluded that gap closure recognized in groups stored in water was directly attributed to water sorption. Martin et al ${ }^{(10)}$ found that hygroscopic expansion might relieve interfacial stresses created during polymerization shrinkage and reduce gaps at tooth restoration interface. Ernst et al ${ }^{(24)}$ found that hybrid resin com- posite used in conjunction with self-etching adhesives revealed better marginal adaptation compared to silorane based composites. Yamasaki et al (25) found that P90 developed the highest cross link density and highest modulus compared to methacrylate based resin composite. Increased modulus of elasticity of P90 could lead to more interfacial shrinkage stresses with more gaps as revealed in the present study. This result disagreed with Palin et al. ${ }^{(3)}$ who found that there was a reduction in microleakage at tooth restoration interface when experimental silorane was used to restore the cavities in comparison with Filtek Z250. Koumpia et al ${ }^{(26)}$ showed that Filtek Silorane and Filtek Z250 showed comparable shear bond strength to dentin regardless of dentin treatment. Papadogiannis et al ${ }^{(27)}$ compared Filtek Silorane to other resin composites and found that although silorane was the most viscous, it showed the best adaptability to cavity walls. However, in their study, prepared specimens were stored in distilled water at $37^{\circ} \mathrm{C}$ for 24 hour unlike the present study.

Considering the effect of $\mathrm{pH}$ on gap dimensions, it was found that changes of $\mathrm{pH}$ of artificial saliva showed no effect on the resulting gap dimensions of Filtek P90 and Filtek supreme XT throughout all tested storage periods. This result confirmed the results found with volumetric changes. Considering the effect of time on gap dimensions, we found nonsignificant effect of storage time on gap dimensions of Filtek P90 and Filtek Supreme XT in acidic and neutral artificial saliva. This contradicted with Reis et al (28) who found that increased time of water storage affected the stability of resin-dentin bonds. They recognized isolated silver grains at the tooth restoration interface that increased in size after 3 months water storage. Duarte Jr. et al ${ }^{(28)}$ found that after aging resin composites for 6 months, intense silver uptake was found at the tooth restoration interface compared to 24 hours. 


\section{CONCLUSIONS}

Under the conditions of the present study, it was concluded that Silorane based resin composite undergoes volumetric dimensional changes comparable to nanohybrid resin composite except on long term storage where it revealed overall contraction at different $\mathrm{pH}$ of storage media. Gap dimensions at tooth/restoration interface of silorane based resin composite was worse compared to that of nanohybrid resin composite especially in neutral $\mathrm{PH}$ media at different periods of time.

\section{REFRENCES}

1. Moreira da Silva E, dos Santos GO, Guimaraes JG, Barcellos Ade A, Sampaio EM. The influence of C-factor, flexural modulus and viscous flow on gap formation in resin composite restorations. Oper Dent. 2007;32(4):356-62

2. Maghaireh GA, Taha NA, Alzraikat H: The Silorane-based Resin Composites: A Review. Oper. Dent., 2017, 42-1, E24-E34

3. Palin W, Fleming G, Burke F, Marquis P and Randall R: The influence of short and medium-term water immersion on the hydrolytic stability of novel low-shrink dental composites. Dent. Mater. 2005, 21, 852-863.

4. Thalacker C, Heumann A, Hampe R, Weinmann W, Guggenberger R, Syrek A. Marginal integrity of silorane and methacrylate restorations after load cycle. J Dent Res 2005; 84(SI-A) [abstr. no. 0277].

5. Palin WM, Fleming GJP, Nathwani H, Burke FJT, Randall RC. In vitro cuspal deflection and microleakage of maxillary premolars restored with novel low-shrink dental composites. Dent Mater 2005; 21:324-35.

6. Weinmann W, Thalacker C, Guggenberger R. Siloranes in dental composites. Dental Materials 2005; 21:68-74.

7. Martin $\mathrm{N}$ and Jedynakiewicz N: Measurment of water sorption in dental composites. Biomat. 1998, 19, 77-83.

8. Versluis A, Tantbirojn D, Lee M, Tu L and Delong R: Can hygroscopic expansion compensate polymerization shrinkage? Part I. Deformation of restored teeth. Dent. Mater. 2011,27, 126-133.

9. Sideridou I, Karabela M and Vouvoudi E: Volumetric dimensional changes of dental light cured dimethacrylate resins after sorption of water or ethanol. Dent. Mater. 2008, 24, 1131-1136.

10. Martin N, Jedynakiewicz N and Fisher A: Hygroscopic expansion and solubility of composite restoratives. Dent. Mater. 2003, 19, 77-86.

11. Ortengren U, Andersson f, Elgh U, Terselius B and Karlsson $\mathrm{S}$ : Influence of $\mathrm{pH}$ and storage time on the sorption and the solubility behavior of three composite resin materials. J Dent. 2001, 29, 35-41.

12. Mariano N, Olivera R, Fernandes M and Rigo E: Corrosion behavior of pure titanium in artificial saliva solution. Revista Matéria 2009, 14, 878 - 880.

13. Lien W and Vandewalle K: Physical properties of new silorane- based restorative system. Dent. Mater. 2010, 26, 337-344.

14. Ilie $\mathrm{N}$ and Hickel R: Macro-, micro- and nano-mechanical investigations on silorane and methacrylate-based composites. Dent. Mater. 2009, 25, 810-819.

15. Prakkia A, Cillia R, Mondellia RFL, Kalachandrab S, Pereiraa JC: Influence of $\mathrm{pH}$ environment on polymer based dental material properties. J Dent. 2005, 33, 91-98.

16. Beech D.R., Bandyopadhyai S. A new laboratory method for evaluating the relative solubility and erosion of dental cements J Oral Rehab. 1983, 10, 57-63

17. Chutinan S, Platt J, Cochran M and Moore B: Volumetric dimensional change of six direct core materials. Dent. Mater. 2004, 20, 345-351.

18. Wie Y, Silikas N, Zhang Z and Watts D: Hygroscopic dimensional changes of self-adhering and new resin-matrix composites during water sorption/desorption cycles. Dent. Mater 2011, 27, 244-252.

19. De Munck J, Van Landuyt K, Peumans, M, Poitevin, A; et al. A Critical Review of the Durability of Adhesion to Tooth Tissue: Methods and Results. J Dent. Res.; 2005, 118-32.

20. Watts D, Kisumbi B and Toworfe G: Dimensional changes of resin/ionomer restoratives in aqueous and neutral media. Dent. Mater. 2000, 16, 89-96.

21. Rüttermann S, Krüger S, Raab W and Janda R: Polymerization shrinkage and hygroscopic expansion of contemporary posterior resin-based filling materials. J Dent. 2007, 35, 806-813.

22. Irie M, Suzuki K, Watts DC Marginal gap formation of light-activated restorative materials: effects of immediate setting shrinkage and bond strength. Dent. Mater., 2002, 18: 203-210. 
23. Peutzfeldt A, Asmussen E: Determinants of in vitro gap formation of resin composites J Dent. 2004, 32, 109-115.

24. Ernst CP, Galler P, Willershausena B, Haller B: Marginal integrity of class V restorations: SEM versus dye penetration Dent. Mater. 2008, $24: 319-327$.

25. Yamasaki LC, Moraes AGV, Barros M, Lewis S, Francci C, Stansbury JW, Pfeifer CS: Polymerization development of "low-shrink" resin composites: Reaction kinetics, polymerization stress and quality of network. Dent. Mater., 2013, 29, 169-179.

26. Koumpia K, Kouros P, Dionysopoulos D \& Zafiriadis L: Bonding strength of silorane-based composite to Er-YAG laser prepared dentin E. Lasers Med Sci (2015) 30:509-516

27. Papadogiannis D, Kakaboura A, Palaghias G, Eliades G: Setting characteristics and cavity adaptation of low-shrinking resin composites. Dent. Mater 2009, 25, 1509-1516.

28. Reis AF, Bedran-russo AKB, Giannini M. \& Pereira PNR. Interfacial ultramorphology of single-step adhesives: nanoleakage as a function of time J Oral Rehab. 2007, 34; 213-221

29. Duarte S Jr., Phark JH, Varjão FM, Sadan A: Nanoleakage, ultramorphological characteristics, and microtensile bond strengths of a new low-shrinkage composite to dentin after artificial aging. Dent. Mater 2009, 25 :589-600 